\title{
Development and validation of a PCR-RFLP test to identify African Rhipicephalus (Boophilus) ticks
}

\author{
Laetitia Lempereur*, Dirk Geysen, Maxime Madder ${ }^{1}$ \\ Institute of Tropical Medicine, Department of Animal Health, Nationalestraat 155, B-2000 Antwerp, Belgium
}

\section{A R T I C L E I N F O}

\section{Article history:}

Received 23 November 2009

Received in revised form 8 January 2010

Accepted 9 January 2010

Available online $\mathrm{xxx}$

\section{Keywords:}

Rhipicephalus (Boophilus)

Identification

PCR-RFLP

Second internal transcribed spacer (ITS2)

Africa

\begin{abstract}
A B S T R A C T
The cattle tick Rhipicephalus (Boophilus) microplus has recently invaded West Africa and caused anxiety amongst farmers in Ivory Coast, as livestock production was severely affected. The introduction of this tick species has remained unnoticed for several years, as all the members of this genus are very similar in appearance. To overcome the cumbersome morphological identification of the four closely related $R$. (Boophilus) spp. in the region, a PCR-RFLP test, based on a part of the second internal transcribed spacer ribosomal DNA (ITS2), was developed.

The molecular tool was successfully validated with a large number of ticks recently collected from West Africa and that were identified both morphologically and genetically. The tool developed is simple, fast, reliable and reproducible; hence it can be routinely applied for species identification.
\end{abstract}

(c) 2010 Elsevier B.V. All rights reserved.

\section{Introduction}

Ticks of the genus Boophilus, recently grouped as a subgenus of Rhipicephalus, are some of the most important tick species in the world from an economical point of view (Estrada-Peña et al., 2006). Five species compose this genus: R. (Boophilus) annulatus, $R$. (Boophilus) decoloratus, R. (Boophilus) geigyi, R. (Boophilus) kohlsi and $R$. (Boophilus) microplus. Rhipicephalus (Boophilus) kohlsi was not included in this study, as it is only present in the Middle East and found exclusively on sheep and goat.

The remaining Boophilus species all colonize Africa and $R$. (Boophilus) microplus, being the most important cattle tick, has only just recently been introduced in West Africa. The recognition of this species amongst the three other closely related Boophilids, endemic in the area, is extremely difficult and could therefore easily be overlooked. The first indication of the introduction of this species was the failure of acaricide treatment as a result of the known high degree of resistance which characterizes this species (George et al., 2004).

In all of the tropical and subtropical areas where $R$. (Boophilus) microplus had been introduced, the tick became a serious hindrance to livestock production. Parasitism by $R$. (Boophilus) microplus results in poor condition, weight loss, reduced meat and milk pro-

\footnotetext{
* Corresponding author. Tel.: +32 4 3664009; fax: +32 43664097.

E-mail addresses: llempereur@ulg.ac.be (L. Lempereur), mmadder@itg.be (M. Madder)

${ }^{1}$ Tel.: +32 32476397 ; fax: +3232476268.
}

duction, and potential transmission of Babesia bovis, B. bigemina and Anaplasma marginale (Estrada-Peña and Venzal, 2006).

Recent publications indicate an extension of the distribution of $R$. (Boophilus) microplus and the displacement of $R$. (Boophilus) decoloratus in different countries like in Tanzania (Lynen et al., 2008) and in South Africa (Tonnesen et al., 2004).

The conventional method to identify $R$. (Boophilus) spp. relies on comparison of morphological characteristics of the different species, which is extremely cumbersome as size and differences between species are limited and sometimes even variable.

To be able to identify $R$. (Boophilus) microplus with certainty and so differentiate the four cattle related $R$. (Boophilus) spp., the development of a PCR-RFLP, based on sequence differences in the second internal transcribed spacer (ITS2), was the main objective of this study.

To validate the test, tick samples from West Africa were collected and identified both morphologically and genetically.

\section{Material and methods}

\subsection{Sources of ticks}

A preliminary cross-sectional tick survey was carried out in West Africa between May 2006 and February 2008 which yielded tick samples from nine countries: Senegal, Togo, Burkina Faso, Guinea-Conakry, Cameroon, Mauritania, Niger, The Gambia and Ivory Coast. In each country between three and 10 cattle were sampled. These ticks were stored in 70\% alcohol, labeled and sent to the Institute of Tropical Medicine in Antwerp (Belgium) for analysis. 


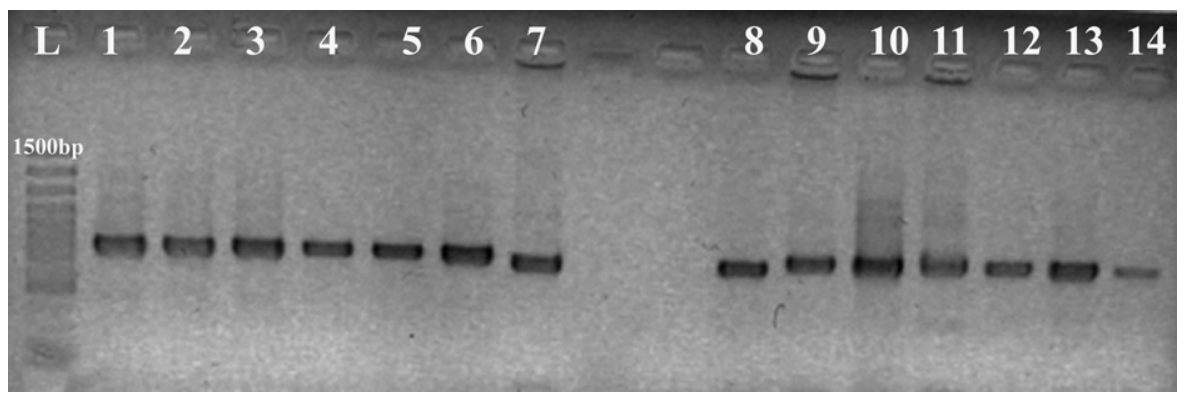

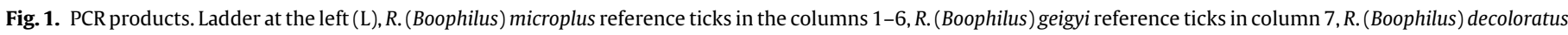
reference ticks in columns 8-10 and $R$. (Boophilus) annulatus reference ticks in columns 11-13, positive control in column 14.

\subsection{Morphological identification}

The first step of the morphological identification of the ticks up the genus level was done using a stereomicroscope (Zeiss Stemi 2000 ) at $60 \times$ magnification. In a next step a microscope (Olympus) at the $100 \times$ magnification was used to identify $R$. (Boophilus) ticks at species level. For the latter, the hypostome dentition, presence of a protuberance bearing setae on palpal segment 1, external spur on coxae II and III, caudal process on male engorged ticks and shape of the internal and external spurs on adanal plates were used as discriminating characteristics (Walker et al., 2003).

The morphological identification of a subset of the ticks was confirmed by Prof. Ivan Horak (Faculty of Veterinary Tropical Diseases, University of Pretoria, South Africa).

\subsection{Development of PCR and RFLP technique}

To develop the PCR and RFLP technique, 27 reference ticks were included: nine Rhipicephalus (Boophilus) microplus adults from Ivory Coast, eight $R$. (Boophilus) decoloratus of which three came from Cameroon, two from Ivory Coast and three from The Gambia. Were also included five R. (Boophilus) geigyi: two from Ivory Coast and three from Guinea as well as five R. (Boophilus) annulatus from Cameroon. The ITS2 region of some morphologically identified specimens was sequenced to confirm the initial identification.

\subsubsection{Primers design}

ITS2 sequences for $R$. (Boophilus) microplus, geigyi, annulatus and decoloratus (GenBank accession nos. U97715, AF271273, $\underline{\text { AF271272 }}$ and $\underline{\text { U97716) }}$ ) were downloaded and aligned using Clustal W software (Thompson et al., 1994). Primers were designed using a DNA computer software program Web primer (http://seq.yeastgenome.org/cgi-bin/web-primer). Amplification was done on the ITS2 gene using the forward primer Boophits2 F 5'-GCC-GTC-GAC-TCG-TTT-TGA-3' and Boophits2 R 5'-TCCGAA-CAG-TTG-CGT-GAT-AAA-3' as reverse primer. GC content and self-annealing was checked on the Oligo Calc web site (http://www.basic.northwestern.edu/biotools/oligocalc.html).

These primers were tested in the Amplix program (http://ifrjr.nord.univ-mrs.fr/AmplifX) and the expected amplicon lengths were estimated. For $R$. (Boophilus) microplus the expected length was $829 \mathrm{bp}$, for $R$. (Boophilus) geigyi $765 \mathrm{bp}$, for $R$. (Boophilus) annulatus $832 \mathrm{bp}$ and for $R$. (Boophilus) decoloratus $821 \mathrm{bp}$.

\subsubsection{DNA extraction}

DNA was extracted using the method of Boom (Boom et al., 1990). This method is based on lytic activity and nuclease inactivating properties of proteinase $\mathrm{K}$ together with the nucleic acid-binding properties of silica particles.

\subsubsection{DNA amplification}

Standard PCR amplifications were carried out in $25 \mu$ l reaction mixtures containing $5 \mu \mathrm{l}$ of the extracted DNA, $1.65 \mathrm{mM} \mathrm{MgCl}$, $0.2 \mathrm{mM}$ of the four dNTPs, $10 \mathrm{pM}$ of each primer, $1 \mathrm{U}$ Taq polymerase enzyme (Promega) and $1 \mu$ l Yellow Sub ${ }^{\mathrm{TM}}$ (GENEO Bioproducts, Hamburg, Germany). The reaction mixture was overlaid by a drop of fine neutral mineral oil (ICN) and placed on a heating block of a programmable thermocycler (Biometra, Westburg). After a denaturation step of $4 \mathrm{~min}$ at $94^{\circ} \mathrm{C}$ each of the 40 cycles consisted of $30 \mathrm{~s}$ at $92^{\circ} \mathrm{C}, 45 \mathrm{~s}$ at $58^{\circ} \mathrm{C}$ and $60 \mathrm{~s}$ at $72^{\circ} \mathrm{C}$ and ended with an extension step of $8 \mathrm{~min}$ at $72^{\circ} \mathrm{C}$.

The mixtures were examined for the presence of DNA fragments by loading $5 \mu \mathrm{l}$ of each reaction mixed with $2 \mu \mathrm{l}$ of loading buffer onto 2\% agarose gels (Sigma). A $1.5 \mathrm{~kb}$ DNA ladder (MBI Fermentas, Lithuania) was loaded on every gel. The samples were run for $20 \mathrm{~min}$ at $100 \mathrm{~V}$, stained in ethidium bromide for $30 \mathrm{~min}$, washed under running tap water and photographed under UV illumination. For further typing of the fragments, RFLP based methods were used.

\subsubsection{Restriction fragment length polymorphism (RFLP)}

Suitable restriction enzymes were identified with the aid of the online tools of The Restriction Enzyme Database (Rebase ${ }^{\circledR}$ http://rebase.neb.com/rebase/rebase.html). Restriction site positions and fragment lengths were determined with DNALC Sequence utilities (http://www.dnalc.org/bioinformatics/ dnalc_nucleotide_analyzer.htm). PCR products were digested by Msp1 enzyme (6U) with $4 \mu \mathrm{l}$ of amplified DNA in $15 \mu \mathrm{l}$ total volume. The reaction was left overnight at $37^{\circ} \mathrm{C}$. Four microliters of all restricted sample mixed with $2 \mu$ l of loading buffer was transferred onto a polyacrylamide gel and a $1 \mathrm{~kb}$ DNA superladder (Eurogentec) was added to all gels for fragment size determination. DNA fragments were separated by vertical electrophoresis in TBE buffer at $100 \mathrm{~V}$ for $2.5 \mathrm{~h}$. The gel was stained using Sybr Green I (Cambrex Bio Science, Rockland, Inc.) during $40 \mathrm{~min}$.

Restriction sites are located for $R$. (Boophilus) microplus at $241 \mathrm{bp}, 311 \mathrm{bp}$ and $408 \mathrm{bp}$, for R. (Boophilus) geigyi at $108 \mathrm{bp}, 323 \mathrm{bp}$, 333 bp, 385 bp, 709 bp, for R. (Boophilus) annulatus at 108 bp, 241 bp, $311 \mathrm{bp}, 408 \mathrm{bp}$ and for $R$. (Boophilus) decoloratus at $107 \mathrm{bp}, 241 \mathrm{bp}$, $311 \mathrm{bp}, 391 \mathrm{bp}, 407 \mathrm{bp}, 442 \mathrm{bp}, 765 \mathrm{bp}$. Thus, in agarose gel, theoretically for $R$. (Boophilus) microplus four bands of $421 \mathrm{bp}, 241 \mathrm{bp}$, $97 \mathrm{bp}$ and $70 \mathrm{bp}$ had to be found. For $R$. (Boophilus) geigyi, six bands of $324 \mathrm{bp}, 215 \mathrm{bp}, 108 \mathrm{bp}, 56 \mathrm{bp}, 52 \mathrm{bp}$ and $10 \mathrm{bp}$. For R. (Boophilus) annulatus five bands of $424 \mathrm{bp}, 133 \mathrm{bp}, 108 \mathrm{bp}, 97 \mathrm{bp}$ and $70 \mathrm{bp}$. For R. (Boophilus) decoloratus eight bands of $323 \mathrm{bp}, 134 \mathrm{bp}, 107 \mathrm{bp}$, 80 bp, 70 bp, 56 bp, 35 bp, 16 bp.

\section{Results}

The morphological identification of 1070 ticks revealed that the $R$. (Boophilus) specimens represented $39 \%$ of the collected ticks, predominantly $R$. (Boophilus) geigyi except in Ivory Coast where $R$. 


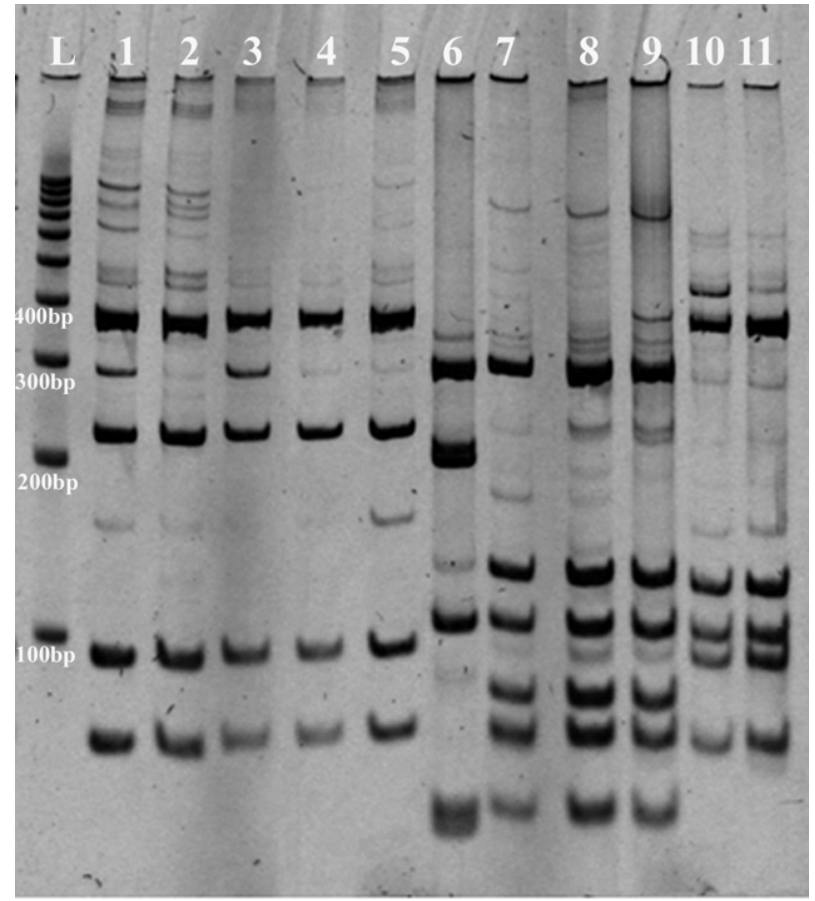

Fig. 2. RFLP profiles. Ladder at the left (L), Rhipicephalus (Boophilus) microplus (bands around $400 \mathrm{bp}, 250 \mathrm{bp}, 100 \mathrm{bp}, 70 \mathrm{bp}$ ) in columns 1-5; R. (Boophilus) geigyi (bands around $300 \mathrm{bp}, 200 \mathrm{bp}, 100 \mathrm{bp}$, and 2 bands around $50 \mathrm{bp}$ ) in the column $6 ; R$. (Boophilus) decoloratus (bands around $300 \mathrm{bp}, 150 \mathrm{bp}, 100 \mathrm{bp}, 80 \mathrm{bp}, 70 \mathrm{bp}, 50 \mathrm{bp}$, $20 \mathrm{bp}$ ) in columns 7-9; R. (Boophilus) annulatus (bands around $400 \mathrm{bp}, 150 \mathrm{bp}$, $100 \mathrm{bp}, 90 \mathrm{bp}, 75 \mathrm{bp}$ ) in column 10 and 11.

(Boophilus) microplus probably overtop all other R. (Boophilus) spp. One third of these Boophilus ticks remained unidentified at species level because of damaged mouthparts.

The 27 reference ticks allowed the development of a PCR-RFLP. This PCR-RFLP allowed then the identification of the damaged Rhipicephalus (Boophilus) ticks.

The PCR amplification gave for 55 tested samples a major product between 765 bp and 832 bp (see Fig. 1) as predicted by Amplix program. The RFLP using Msp I digestion gave very distinct profiles differentiating the four Rhipicephalus (Boophilus) species as theoretically expected (see Fig. 2).

The profile of $R$. (Boophilus) annulatus showed five bands on agarose gel (around 400 bp, 150 bp, 100 bp, 90 bp, 75 bp) (see Fig. 2 columns 10-11), whereas $R$. (Boophilus) microplus showed four bands (around 400 bp, 250 bp, 100 bp, 70 bp) (see Fig. 2 columns 1-5). Rhipicephalus (Boophilus) geigyi was characterized by 5 bands (around $300 \mathrm{bp}, 200 \mathrm{bp}, 100 \mathrm{bp}$, and 2 bands around $50 \mathrm{bp}$ ). One band of $10 \mathrm{bp}$ is missing due to the very short length of this fragment (see Fig. 2 column 6).

Rhipicephalus (Boophilus) decoloratus showed 7 different bands (around $300 \mathrm{bp}, 150 \mathrm{bp}, 100 \mathrm{bp}, 80 \mathrm{bp}, 70 \mathrm{bp}, 50 \mathrm{bp}, 30 \mathrm{bp}$ ). One band of $16 \mathrm{bp}$ was missing also due to the very short length of this fragment (see Fig. 2 columns 7-9).

\section{Discussion}

The genus Boophilus consists of five species of which three were present in West Africa for many years: $R$. (Boophilus) annulatus, $R$. (Boophilus) decoloratus and R. (Boophilus) geigyi. In 2007, $R$. (Boophilus) microplus, an important vector of Babesia bovis, had been identified for the first time in this region where it now seems to cause major problems in dairy farms (Madder et al., 2007) (unpublished data). The introduction most likely occurred during one of the imports of Girolando cattle from Brazil, and this to improve local cattle breeds. The most important questions however, still remains unanswered: when was this tick introduced? It appears that private persons undertook several import actions the last decade. Before 2007 and after the first import of Girolando probably in 2000 , no published data are available of the presence or absence of $R$. (Boophilus) microplus.

As outlined in the introduction, the morphological differences between some of the species of this genus are extremely small and some of the characteristics also seem to be variable. The difference between females of $R$. (Boophilus) microplus and $R$. (Boophilus) annulatus is almost exclusively based on the presence or size of the external spurs of the second and third coxae. It was however observed that some specimens originating from Cameroon did show external spurs although the size and shape was somewhat different from those of $R$. (Boophilus) microplus. The hypostome dentition has been described to be variable as well, $R$. (Boophilus) decoloratus sometimes presents a dentition of $3.5 \times 3.5$ (Hoogstraal, 1956). In this study we also observed $R$. (Boophilus) microplus with a dentition of $4.5 \times 4.5$ (three or four extra teeth in between the inner rows). The same applies to the shape of the spurs of the adanal plates of the males, which might be extremely variable in the case of $R$. (Boophilus) microplus. If the latter species would have been introduced in an area, it could have easily been overlooked, especially when ticks were damaged during collection or not cleaned thoroughly before identification. Especially female ticks are extremely difficult to identify and without males, which are easily been overlooked due to their small size, the presence of $R$. (Boophilus) microplus is extremely difficult to validate. In fact, morphological identification is far from specific, time consuming and requires sufficient expertise on different populations of the species in question. The molecular tool that was implemented represents a valuable aid for identification and would allow confirmation or disproval of previous or historical identifications.

The first results of the PCR-RFLP tool yielded species-specific profiles and as all the screened populations of the same species originating from different countries showed consistent profiles, the test could therefore be used as a golden standard for tick identification of this genus in the region. The only restriction for the identification of $R$. (Boophilus) microplus might be the populations from Australia as recent studies have concluded the Australia strain not being able any more of producing fertile crosses with Africa and Latin American strains and being genetically different (Labruna et al., 2009).

The presence of $R$. (Boophilus) microplus in Ivory Coast was confirmed without any doubt. The samples that were collected in this country only presented $R$. (Boophilus) microplus, indicating that a recent introduction into this area seems unlikely or extremely successful. From all other countries in this study no R. (Boophilus) microplus were identified so far. It must however be mentioned that the number of samples screened was fairly low and consequently this should be confirmed.

Future investigations are needed to determine the real extent of the presence of $R$. (Boophilus) microplus in Ivory Coast and neighboring countries and the effect on the transmission dynamics of Babesia spp. present in the area. To secure livestock production, improvement of cattle breeds and the import of exotic cattle breeds, the development of this reliable tool could offer opportunities for surveillance of ticks on cattle especially during importation.

\section{Acknowledgement}

Camille Hela Foundation of Liège University Belgium are acknowledged for their financial support.

The members of the ITM alumni network are thanked for the collections of ticks in the respective countries: Kokou Emmanuel Deka (Benin), Thérèse Roseline Sidpayété Nana (Burkina Faso), Roger 
Ngambia Funkeu (Cameroon), Arss Secka (The Gambia), Barry Alpha Madiou (Republic of Guinea), Barry Yahya (Mauritania), Ibrahima Mahamadou (Niger), Ibrahima Deme, Souaïbou Diouf and Amadou Sow (Senegal).

Prof. Ivan Horak, Department of Veterinary Tropical Diseases, University of Pretoria, South Africa, is acknowledged for the morphological confirmation of a subset of the collected ticks.

\section{References}

Boom, R., Sol, C.J., Salimans, M.M., Jansen, C.L., Wertheim-van Dillen, P.M., van der Noordaa, J., 1990. Rapid and simple method for purification of nucleic acids. J. Clin. Microbiol. 28, 495-503.

Estrada-Peña, A., Corson, M., Venzal, J.M., Mangold, A.J., Guglielmone, A., 2006. Changes in climate and habitat suitability for the cattle tick Boophilus microplus in its southern Neotropical distribution range. J. Vect. Ecol. 31, 158-167.

Estrada-Peña, A., Venzal, J.M., 2006. High-resolution predictive mapping for Boophilus annulatus and B. microplus (Acari: Ixodidae) in Mexico and Southern Texas. Vet. Parasitol. 142, 350-358.

George, J.E., Pound, J.M., Davey, R.B., 2004. Chemical control of ticks on cattle and the resistance of these parasites to acaricides. Parasitology 129 (Suppl.), S353-S366.
Hoogstraal, H., 1956. African Ixodoidea, Ticks of the Sudan, vol. 1. US Department of the Navy, Bureau of Medicine and Surgery, Washington, D.C..

Labruna, M.B., Naranjo, V., Mangold, A.J., Thompson, C., Estrada-Peña, A., Guglielmone, A.A., Jongejan, F., de la, F.J., 2009. Allopatric speciation in ticks: genetic and reproductive divergence between geographic strains of Rhipicephalus (Boophilus) microplus. BMC Evol. Biol. 9, 46-.

Lynen, G., Zeman, P., Bakuname, C., Di Giulio, G., Mtui, P., Sanka, P., Jongejan, F., 2008 Shifts in the distributional ranges of Boophilus ticks in Tanzania: evidence that a parapatric boundary between Boophilus microplus and B. decoloratus follows climate gradients. Exp. Appl. Acarol. 44, 147-164.

Madder, M., Thys, E., Geysen, D., Baudoux, C., Horak, I., 2007. Boophilus microplus ticks found in West Africa. Exp. Appl. Acarol. 43, 233-234.

Thompson, J.D., Higgins, D.G., Gibson, T.J., 1994. CLUSTAL W: improving the sensitivity of progressive multiple sequence alignment through sequence weighting position-specific gap penalties and weight matrix choice. Nucleic Acids Res. 22, 4673-4680.

Tonnesen, M.H., Penzhorn, B.L., Bryson, N.R., Stoltsz, W.H., Masibigiri, T., 2004 Displacement of Boophilus decoloratus by Boophilus microplus in the Soutpansberg region, Limpopo Province, South Africa. Exp. Appl. Acarol. 32, 199208.

Walker, A.R., Bouattour, A., Camicas, J.L., Estrada-Peña, A., Horak, I., Latif, A., Pegram, R., Preston P.M., 2003. Ticks of Domestic Animals in Africa: A Guide to Identification of Species, vol. 1, Bioscience Reports, Scotland, UK. 